\title{
Mortality from Cardiovascular Disease in Bahia
}

\author{
Gilson Feitosa ${ }^{1,2}$ \\ Escola Bahiana de Medicina e Saúde Publica, 'Salvador, BA - Brazil \\ Hospital Santa Izabel, ${ }^{2}$ Salvador, BA-Brazil \\ Editorial referring to the article: Mortality Trends from Cardiovascular Diseases in the State of Bahia, Brazil, between 2000 and 2015
}

The adoption of preventive measures against cardiovascular diseases based on greater knowledge and dissemination of information regarding the risk factors that determine their occurrence, has positively modified the incidence of these diseases, especially those of atherosclerotic or hypertensive nature. This is a worldwide record. ${ }^{1}$

However, two factors must be considered: first, cardiovascular disease continues to be the main cause of death in the contemporary world, and second, this favorable reduction behavior is not seen evenly everywhere. ${ }^{2}$

Socioeconomic, cultural, and educational nature factors can also cause difficulties in the application of well-established principles.

The authors Nascimento and Latado ${ }^{3}$ through careful observation, suggest that in the state of Bahia, when viewed unadjusted, there is the impression that cardiovascular diseases do not show a reduction in their occurrence. When the data are adjusted for age, the tendency to increase cardiovascular mortality in the older age groups stands out.

It should be considered that the data provided by DATASUS and IBGE for this survey may conceptually offer some imprecision element, as it happens in surveys of this type, with no data adjudication. However, they have improved ${ }^{4}$ and are the best available data and should be used for the analysis and adoption of public health measures.

\section{Keywords}

Cardiovascular Diseases/mortality; Epidemiology; Prevention and Control; Risk Factors; Atherosclerosis; Hypertension.
It is expected that with the progressive increase in life expectancy, a greater representation of larger age groups will be obtained, as can be seen with the gradual thickening of the higher parts of the Brazilian age pyramid.

However, this would not explain the increase seen with the adjustment for age.

Notably smoking, a significant risk factor for cardiovascular diseases, particularly coronary heart disease, had a considerable reduction in the Brazilian population and especially among Bahians.

It should be emphasized, however, that some characteristics of the Bahian population may have changed during the observation period, bringing an element of confusion when comparing their behavior with the one from other places where society offers more elements of stability of their social characteristics. Such facts have been recorded in some parts of the world. ${ }^{5}$ For example, in Brazil as a whole and especially in Bahia, there was an unplanned urbanization of cities and consequently poor housing conditions. Therefore, as a result, younger people have less education opportunities and older people have less access to medical care.

On the other hand, despite the commendable public health coverage offered by the Unified Health System (SUS), for various reasons, the results obtained in the treatment of acute coronary syndromes are consistently demonstrated to have inferior results compared to the patients treated by the private health system - contributing factors are a lower degree of information, which delays the start of treatment and, possibly, the less availability of more advanced resources for treatment in SUS patients. ${ }^{5}$

It is an undisputable fact that recently there has been a decline in the private health system coverage in Bahia, which increases the representation of SUS patients.

Mailing Address: Gilson Feitosa

Rua Florida, 211, apto: 302. Postal Code: 40050-480, Salvador, BA - Brazil

E-mail: gilson-feitosa@uol.com.br, gfeitosa@me.com 


\section{References}

1. Shepard D, VanderZanden A, Moran A, Naghavi M, Murray C and Roth G. Ischemic Heart Disease Worldwide, 1990 to 2013: Estimates From the Global Burden of Disease Study 2013. Circ Cardiovasc Qual Outcomes. 2015;8(4):455-6.

2. de Andrade L, Zanini V, Batilana AP, de Carvalho EC, Pietrobon R, Nihei OK and de Barros Carvalho MD. Regional disparities in mortality after ischemic heart disease in a Brazilian state from 2006 to 2010. PLoS One. 2013;8:e59363.

3. Nascimento YM, Latado AL. Mortality trends from cardiovascular diseases in the state of Bahia, Brazil, between 2000 and 2015. Int J Cardiovasc Sci.2020;33(6):656-65.
4. Franca EB, Ishitani LH, Teixeira RA, Cunha CCD and Marinho MF. Improving the usefulness of mortality data: reclassification of ill-defined causes based on medical records and home interviews in Brazil. Rev Bras Epidemiol. 2019;22(Suppl 3):e190010.

5. Razvodovsky YE. Psychosocial distress as a risk factor of ischemic heart disease mortality. Psychiatr Danub. 2013;25(1):68-75.

6. Oliveira JC, Almeida-Santos MA, Cunha-Oliveira J, Oliveira LCS, de Carvalho Barreto ID, Clair Remacre Munareto Lima T, et al. BarretoFilho JA and Investigators VR. Disparities in Access and Mortality of Patients With ST-Segment-Elevation Myocardial Infarction Using the Brazilian Public Healthcare System: VICTIM Register. J Am Heart Assoc. 2019;8(20):e013057. 